\title{
Analysis of Deformation and Strength of Solar Module Support under Wind-Wave Load
}

\author{
Hong $\mathrm{Li}^{1, \mathrm{a}^{*}}$, Dongxu Zhang ${ }^{1, \mathrm{~b}}$, Zhongwen Qin ${ }^{2, \mathrm{c}}, \mathrm{Li} \mathrm{Li}^{3, \mathrm{~d}}$ and Enguo Zhang ${ }^{2, \mathrm{e}}$ \\ ${ }^{1}$ College of Aerospace and Civil Engineering, Harbin Engineering University, Harbin 150001, China \\ ${ }^{2}$ Dalian Shipbuilding Industry Co.,Ltd., Dalian 116000, China \\ ${ }^{3}$ College of Materials Science and Chemical Engineering, Harbin Engineering University, Harbin \\ 150001, China \\ alihong@hrbeu.edu.cn, ${ }^{b} 525731752 @ q q . c o m,{ }^{c}$ qinzhongwen@dsic.cn, ${ }^{d}$ lili_heu@hrbeu.edu.cn, \\ ezhang_enguo@dsic-design.cn \\ ${ }^{*}$ Corresponding author
}

Keywords: Solar module support, Stress, Displacement, Wind load, Wave load.

Abstract. Solar energy is one of the most important renewable energy, and it will not cause pollution and damage to the environment, using PV solar energy collection devices to generate electricity for the ship will be expected. When PV module supports are installed on the ship's deck, the wind and wave loads are the main environmental loads for them to bear. Based on fluid-solid coupling analysis and CCS tanker direct calculation rules, the deformation and strength of PV module supports under wind loads in three different wind speeds and wave loads are studied and the requirements of strength and deformation of the PV module support are satisfied. The design of the PV module support in this paper is suitable for marine environment under strong wind loads and wave loads on the deck.

\section{Introduction}

Solar energy is one of the most important renewable energy, and it will not cause pollution and damage to the environment. Solar energy is the development direction of new energy used in the ship that the solar photovoltaic (PV) modules are spread on the hull deck in the form of arrays and the solar energy is collected in order to provide energy for the ship by using the PV modules [1].

The use and development of solar energy has become the research direction of all countries in the world. Germany has had a grand scale in developing and using solar energy. In 2012, the two companies Conergy and Spercheios in Germany together researched and developed four power stations for Greek whose power generation capacity reached $1 \mathrm{MW}$. In the area of ship, PV module industry is also in rapid progress and development in China. In 2010, the first solar powered ship with the mixed power of solar energy and oil being researched and developed by Chinese was displayed on Shanghai World Exposition.

When being installed PV modules on the deck and sailing, the structural safety of the solar ship and PV modules should be considered adequately. As common environmental loads, the wind load and wave load play the important role on the destruction of module support. The research of them can improve the security and economy of installing PV module support [2].

\section{Flow Field Analysis for PV Module}

The PV module supports being installed on the deck of a large oil tanker are researched in this paper. The deformation and strength of PV module support under wind-wave load are mainly studied. The tempered glass occupies the main thickness of the laminated parts of PV modules and mainly bears wind-wave loads under working condition. So the laminated parts of PV modules are simplified to the model consisting of tempered glass when studying the wind-wave load. Its size is $1470 \mathrm{~mm}$ $\times 680 \mathrm{~mm} \times 25 \mathrm{~mm}$. The material of module frame is aluminum alloy. The model of PV module is shown as Fig.1. 


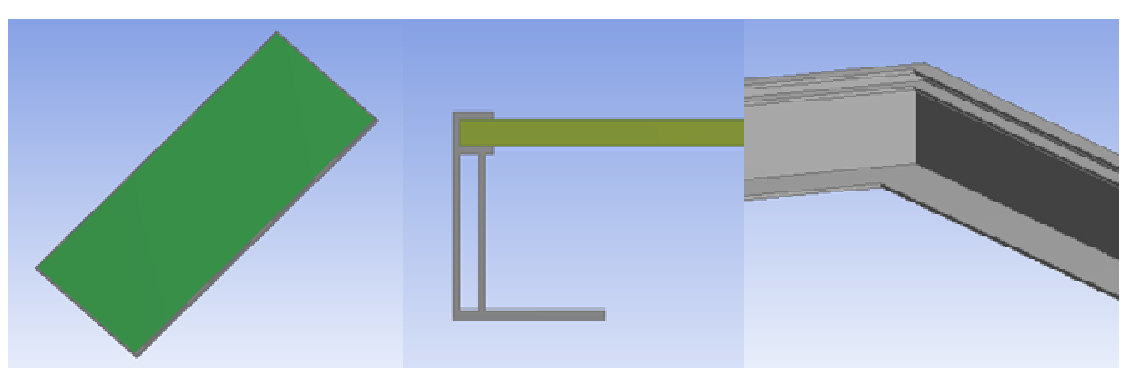

Fig.1 Solar PV Module

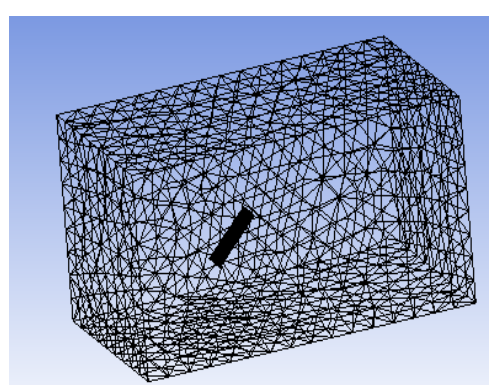

Fig.2 Flow Field Model

Oil tanker runs on the sea, the wind is generally stable 4-5 grade. Wind conditions can be extended to 13-18 level under bad weather. The flow field analysis [3,4] of three wind speeds of $32 \mathrm{~m} / \mathrm{s}$ (Beaufort scale 11), 42m/s (Beaufort scale14) and $50 \mathrm{~m} / \mathrm{s}$ (Beaufort scale 15) is carried out respectively in software fluent in this paper and the flow pressure on the PV module under different wind speeds is obtained.

When the flow field is simulated, the inclined angle of the PV module is $30^{\circ}$ and the wind direction is $90^{\circ}$. The flow field model of the PV module is shown in Fig. 2. The pressure distribution of flow field of three kinds of wind speed is get. The trends of distribution of pressure of different wind speeds are roughly the same.The pressure being withstood by the windward surface is greater than that of the leeward side and the pressure of PV module near the air inlet end is greater than that far away from the inlet end. When the wind speed is $50 \mathrm{~m} / \mathrm{s}$, the maximum of pressure being applied on the PV module is $1630 \mathrm{~Pa}$. The curves of wind pressure along the length direction of solar panel under three different wind speeds are obtained from the flow field analysis as shown in Fig.3.

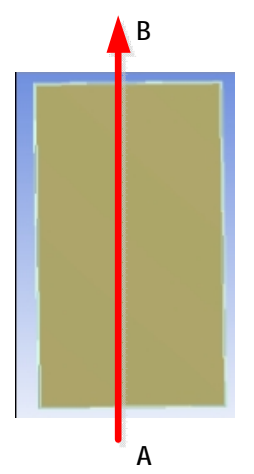

(a)

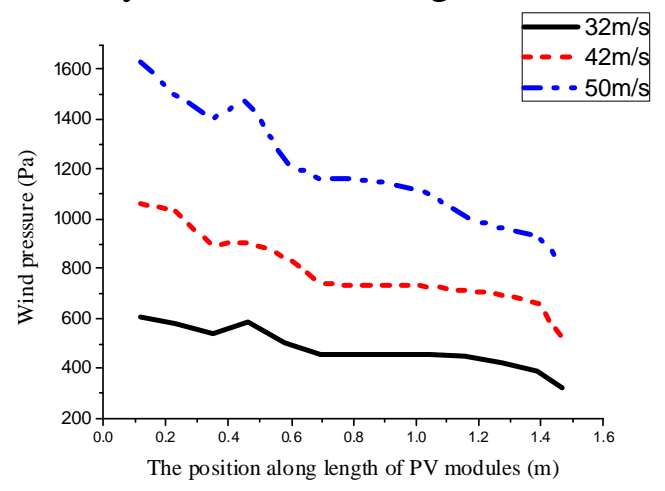

(b)

Fig.3 Curves of Wind Load

According to the installation manual for a solar PV module, when the PV module is installed following the way suitable for most of environments, the allowed maximum of static pressure being applied on the windward surface of the PV module is $2400 \mathrm{~Pa}$. Studying the results in this paper, it can be noticed that the maximum of pressure on the windward surface of the PV module is smaller than $2400 \mathrm{~Pa}$ when the wind speed is $32 \mathrm{~m} / \mathrm{s}, 42 \mathrm{~m} / \mathrm{s}$ and $50 \mathrm{~m} / \mathrm{s}$ respectively. The results are in accordance with the safety requirements.

\section{Deformation and Strength Analysis for Module Support}

The PV modules and supports consist of solar panels and brackets. They are installed by multi-row assembly on the safety area of deck of oil tanker as shown in Fig.4. There are 126 rows of PV modules being arranged symmetrically on the deck of a 300,000 tons VLCC tanker in this paper. The material of support is steel. The weight of the modules and supports are about 78 tons, which has little influence on the ship's center of buoyancy and stable performance of the ship. 

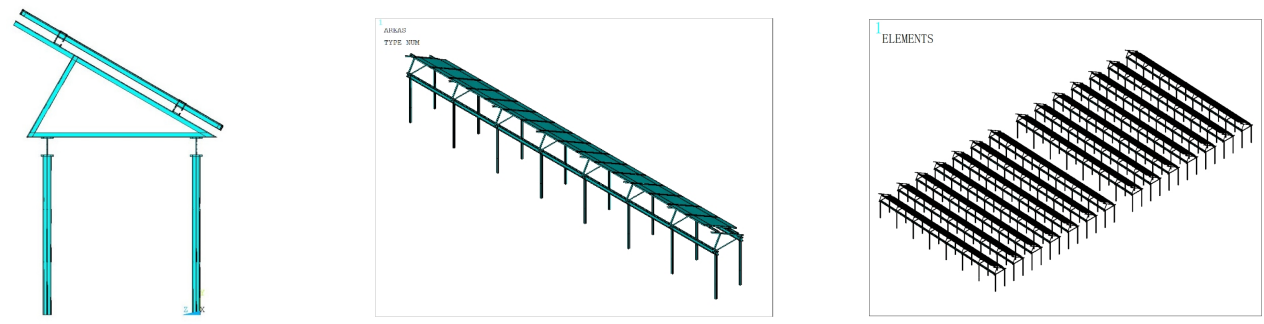

Fig.4 PV Modules and Supports

When the oil tanker installed PV modules shipping out, the wind load and wave load are very important environmental loads. According to CCS tanker direct calculation rules, the wave load on the deck is calculated. Transferring the wind load and wave load to the PV module, the results of the stress and deformation of PV module and support are obtained based on structural static analysis by using software ansys.

The total displacement and Mises stress of PV module support under $32 \mathrm{~m} / \mathrm{s}$ wind speed are calculated. As shown in Fig.5, the maximum of displacement of PV module is $6 \mathrm{~mm}$ and occurs at the underside of the aluminum alloy frame. The maximum of Mises stress is $185 \mathrm{Mpa}$ and occurs at the junction of support in the bracket where the thickness is much smaller than other sizes. The stresses of PV module support are much smaller than yield stress of steel at other parts. The maximum of Mises stress of solar panel is $12.5 \mathrm{Mpa}$, coming at the mounting holes of aluminum alloy frame. Because the mounting holes are restrained, the stress concentration happens. The distribution of Mises stress on tempered glass is nearly uniform. So the PV module support satisfies with the requirements of strength and deflection.

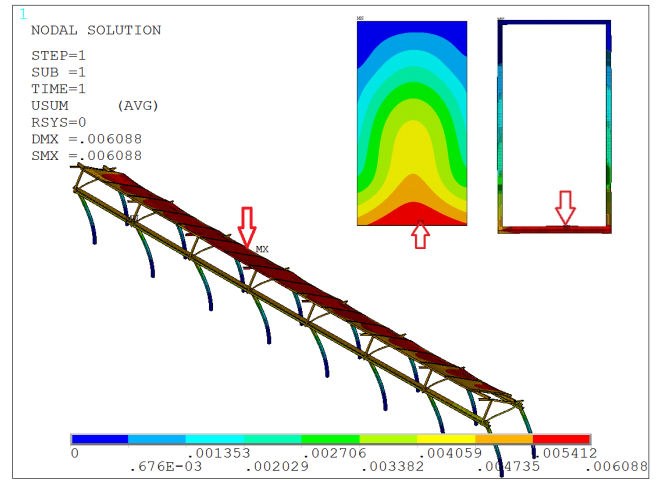

(a) Deformation of PV module

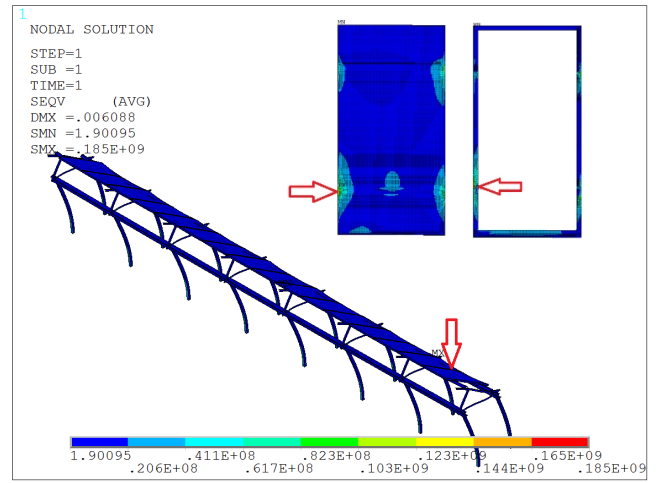

(b) Mises stress of PV module

Fig.5 Results of Structural Static Analysis (wind speed of $32 \mathrm{~m} / \mathrm{s}$ )

The total displacement and Mises stress of PV module support under $42 \mathrm{~m} / \mathrm{s}$ wind speed are calculated. As shown in Fig.6, the maximum of displacement of PV module is $9 \mathrm{~mm}$ and occurs at the underside of the aluminum alloy frame. The maximum of Mises stress is $265 \mathrm{Mpa}$ and occurs at the junction of support in the bracket where the thickness is much smaller than other sizes. The stresses of PV module support are much smaller than yield stress of steel at other parts. The maximum of Mises stress of solar panel is $19.1 \mathrm{Mpa}$, coming at the mounting holes of aluminum alloy frame. Because the mounting holes are restrained, the stress concentration happens. The distribution of Mises stress on tempered glass is nearly uniform and less than 10Mpa. So the PV module support satisfies with the requirements of strength and deflection.

The total displacement and Mises stress of PV module support under $50 \mathrm{~m} / \mathrm{s}$ wind speed are calculated. As shown in Fig.7, the maximum of displacement of PV module is $13 \mathrm{~mm}$ and occurs at the underside of the aluminum alloy frame. The maximum of Mises stress also occurs at the junction of support in the bracket where the stress concentration happens. The stresses of PV module support are much smaller than yield stress of steel at other parts. The maximum of Mises stress of solar panel is 27.9Mpa, coming at the mounting holes of aluminum alloy frame. Because the mounting holes are 
restrained, the stress concentration happens. The distribution of Mises stress on tempered glass is nearly uniform. The PV module support satisfies with the requirements of strength and deflection.

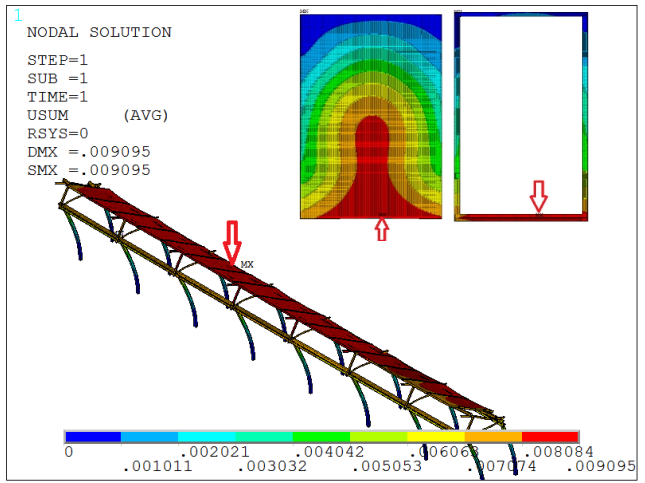

(a) Deformation of PV module

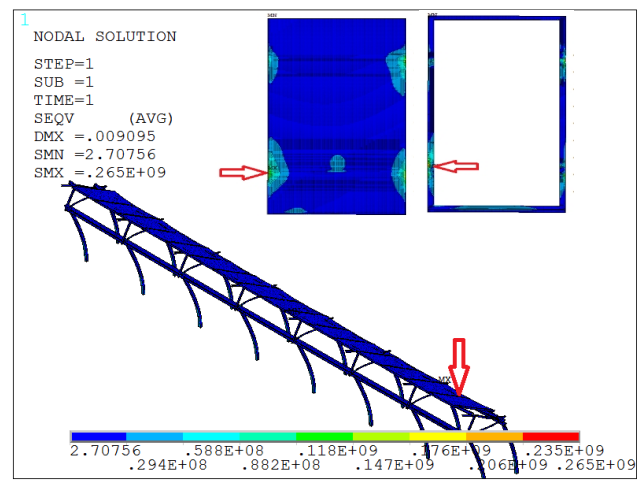

(b) Mises stress of PV module

Fig.6 Results of Structural Static Analysis (wind speed of $42 \mathrm{~m} / \mathrm{s}$ )

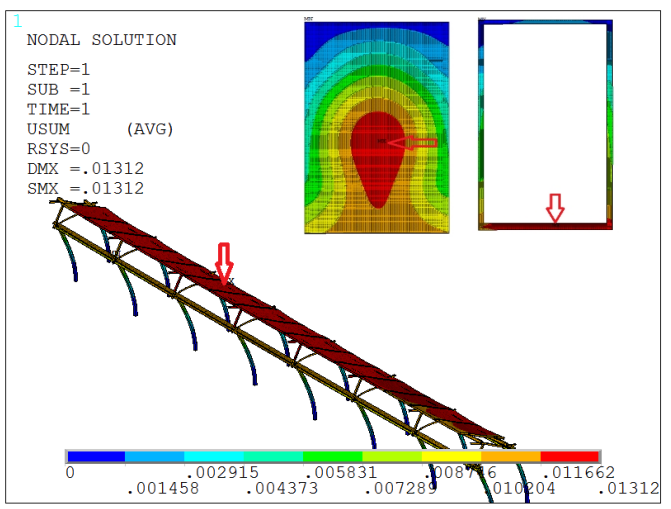

(a) Deformation of PV module

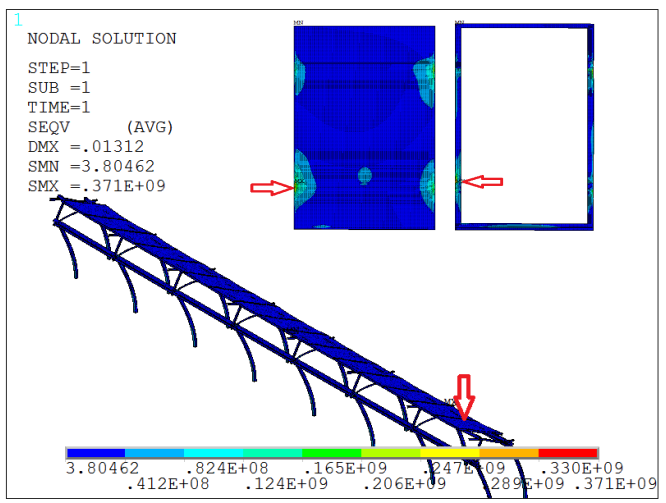

(b) Mises stress of PV module

Fig.7 Results of Structural Static Analysis (wind speed of 50m/s)

\section{Summary}

By flow field analysis in three wind speeds of $32 \mathrm{~m} / \mathrm{s}, 42 \mathrm{~m} / \mathrm{s}$ and $50 \mathrm{~m} / \mathrm{s}$ respectively, the wind pressure applying on the PV module is obtained. The trends of distribution of wind load in different wind speeds are roughly the same. The wave load is based on CCS tanker direct calculation rules. The displacements and Mises stresses of PV module and support are calculated and the results are compared and analyzed in this paper. The requirements of strength and deformation of the PV module support are all satisfied in different wind speeds. Therefore, the design of the PV module support is suitable for the marine environment under the strong wind load and the wave load on the deck.

\section{References}

[1] Yan Xinping, Progress Review of New Energy Application in Ship, Ship and Ocean Engineering, 2010, 39(6), pp.111-115+120

[2] Wang Chao, Safety Assessment of Oil Tanker under Large Wind and Waves, $\mathrm{PhD}$ thesis, Dalian Maritime University, Dalian, China, 2009.

[3] HeJu, Zhu Rui and Wang Jianbo, Numerical Simulation of Photovoltaic Cells under Wind Load, Solar Energy, 2013, 16, pp.56-58.

[4] Anil Singh Yadav and J.L.Bhagoria, Heat Transfer and Fluid Flow Analysis of Solar Air Heater: A review of CFD approach, Renewable and Sustainable Energy Reviews, 2013, 23. 